\title{
The Mammalian Cone Visual Cycle Promotes Rapid M/L-Cone Pigment Regeneration Independently of the Interphotoreceptor Retinoid-Binding Protein
}

\author{
Alexander V. Kolesnikov, ${ }^{1}$ Peter H. Tang, ${ }^{2}$ Ryan 0. Parker, ${ }^{2}$ Rosalie K. Crouch, ${ }^{3}$ and Vladimir J. Kefalov ${ }^{1}$ \\ ${ }^{1}$ Department of Ophthalmology and Visual Sciences, Washington University School of Medicine, St. Louis, Missouri 63110, Departments of ${ }^{2}$ Neuroscience \\ and ${ }^{3}$ Ophthalmology, Medical University of South Carolina, Charleston, South Carolina 29425
}

\begin{abstract}
Rapid regeneration of the visual pigment following its photoactivation is critical for the function of cone photoreceptors throughout the day. Though the reactions of the visual cycle in the retinal pigment epithelium (RPE) that recycle chromophore for rod pigment regeneration are well characterized, the corresponding mechanisms that enable rapid regeneration of cone pigment are poorly understood. A key remaining question is the relative contribution of the recently discovered cone-specific retina visual cycle and the classic RPEdependent visual cycle to mammalian cone pigment regeneration. In addition, it is not clear what role, if any, the abundant interphotoreceptor retinoid-binding protein (IRBP) presumed to facilitate the traffic of chromophore, plays in accelerating mammalian cone pigment regeneration. To address these issues, we used transretinal recordings to evaluate $\mathrm{M} / \mathrm{L}$-cone pigment regeneration in isolated retinas and eyecups from control and IRBP-deficient mice. Remarkably, the mouse retina promoted M/L-cone dark adaptation eightfold faster than the RPE. However, complete cone recovery required both visual cycles. We conclude that the retina visual cycle is critical for the initial rapid regeneration of mouse $\mathrm{M} / \mathrm{L}$-cone pigment during dark adaptation, whereas the slower RPE visual cycle is required to complete the process. While the deletion of IRBP reduced the amplitude and slowed the kinetics of mouse M/L-cone photoresponses, cone adaptation in bright, steady light and the kinetics of cone dark adaptation were not affected in isolated retina or in intact eyecup. Thus, IRBP does not accelerate cone pigment regeneration and is not critical for the function of mouse M/L-cones in bright light.
\end{abstract}

\section{Introduction}

The vertebrate retina has two distinct classes of photoreceptors, rods and cones, that mediate nighttime and daylight vision, correspondingly. Their outer segments contain photosensitive visual pigments (rhodopsin in rods and cone pigment in cones), consisting of a visual chromophore (11-cis-retinal) covalently bound to rod- or cone-specific apo-protein, opsin. Activation of the visual pigment by light not only triggers the phototransduction cascade to produce cellular photoresponse but also results in decay of the pigment into all-trans-retinal and free opsin. Recycling of retinal to its 11-cis-form and regeneration of the photoactivated, or bleached, visual pigment is achieved in a complex chain of biochemical reactions called the visual cycle. Until recently, the only known mechanism for recycling chromophore for vertebrate rods and cones was through the well characterized retinal

Received Jan. 26, 2011; revised March 24, 2011; accepted April 14, 2011.

Author contributions: A.V.K., P.H.T., R.O.P., R.K.C., and V.J.K. designed research; A.V.K., P.H.T., and R.O.P. performed research; A.V.K., P.H.T., and R.O.P. analyzed data; A.V.K., R.K.C., and V.J.K. wrote the paper.

This work was supported by NIH Grants EY019312 (V.J.K.), EY004939 (R.K.C.), and EY002687 to the Department of Ophthalmology and Visual Sciences at Washington University; and by Research to Prevent Blindness: Career Development Award (V.J.K.), a Senior Scholars Award (R.K.C), and Medical Student Research Fellowships (P.H.T. and R.0.P). We thank Janis Lem for the $T \alpha^{-/-}$animals and Gabriel Travis for the Irbp ${ }^{-/-}[12952 / S v]$ animals. We are also grateful to Carter Cornwall and Gabriel Travis for their comments on the manuscript.

Correspondence should be addressed to either Dr. Alexander V. Kolesnikov or Dr. Vladimir J. Kefalov, Department of Ophthalmology and Visual Sciences, Washington University in Saint Louis, 660 South Euclid Avenue, Saint Louis, M0 63110. E-mail: kolesnikov@wustl.edu or kefalov@wustl.edu.

DOI:10.1523/JNEUROSCI.0438-11.2011

Copyright $\odot 2011$ the authors $\quad 0270-6474 / 11 / 317900-10 \$ 15.00 / 0$ pigment epithelium (RPE) visual cycle (for review, see Fain et al., 1996; Saari, 2000; Lamb and Pugh, 2004). This pathway involves the cells in the RPE where all-trans-retinol, released from photoreceptors following a bleach, is converted back into 11-cis-retinal and then used by rods and cones for pigment regeneration. Recently, biochemical and physiological studies have demonstrated the function of a second, cone-specific visual cycle in the neural retina (for review, see Fleisch and Neuhauss, 2010; Wang and Kefalov, 2011). In this pathway, all-trans-retinol is isomerized to 11-cis-retinol in glial Müller cells and then oxidized selectively in cones to 11-cis-retinal for pigment regeneration.

Rapid pigment regeneration is critical for the ability of cones to maintain sufficient pigment levels in steady, bright bleaching illumination and also to dark adapt rapidly following exposure to intense light. The mechanisms that recycle chromophore and drive the rapid pigment regeneration in mammalian cones have not been well characterized, and two key issues remain unresolved. First, the relative contributions of the retina and RPE visual cycles to the recovery of mammalian cone photosensitivity are unknown. Though in amphibians the two visual cycles have comparable rates and contribute equally to cone pigment regeneration (Wang et al., 2009), the case in the heavily rod-dominant mammalian retina is unclear. Second, it is not clear how cone pigment regeneration is modulated by chromophore-binding proteins, such as interphotoreceptor retinoid-binding protein (IRBP), an abundant component of the interphotoreceptor matrix (Fong et al., 1984; Redmond et al., 1985). Although IRBP has 
been suggested to play an important role in maintaining cone structure and function by facilitating retinoid transport between cones and the RPE (Ripps et al., 2000; Jin et al., 2009; Parker et al., 2009), its effect on cone pigment regeneration remains unknown. These questions have been difficult to test physiologically due to the low (3\%) fraction of cones in the mouse retina (CarterDawson and LaVail, 1979) producing a barely detectable cone ERG a-wave that is masked by much larger rod response and cone b-wave of inverse polarity. To circumvent this technical issue, we adopted a method for transretinal recordings from intact mouse eyecups. We used this method and evaluated mouse M/Lcone pigment regeneration in isolated retinas and intact eyecups from control and IRBP-deficient mice.

\section{Materials and Methods}

Animals. Irbp ${ }^{+/+} T \alpha^{-/-}$and Irbp ${ }^{-/-} T \alpha^{-/-}$mouse lines were derived from crossing between original Irbp ${ }^{-/-}$(C57BL/6 background, Met450 variant of RPE65) mice (Liou et al., 1998) and rod transducing $\alpha$-subunit knock-out animals ( $\mathrm{T}^{-{ }^{--}}, \mathrm{BALB} / \mathrm{c}$ background, Leu450 variant of RPE65) that lack rod signaling (Calvert et al., 2000). All Irbp ${ }^{+/+} T \alpha^{-/-}$ and $I r b p^{-1-} T \alpha^{-1-}$ mice used in this study (of either sex) were homozygous for the Leu 450 allele of Rpe 65 as determined by genotyping protocol described previously (Grimm et al., 2004). When specified, mice of the following strains (of either sex) were also used: C57BL/6 (Met450 variant of RPE65, Jackson Laboratories), original $\mathrm{Irbp}^{-/-}$(C57BL/6 background, Met450 variant of RPE65) (Liou et al., 1998), 129S2/Sv (Leu450 variant of RPE65, Charles River Laboratories), and Irbp ${ }^{-1-}$ (129S2/Sv background, Leu450 variant of RPE65) (Jin et al., 2009), generously provided by G. Travis (Jules Stein Eye Institute, Los Angeles, CA). Adult animals (1-2 months old) were used in all experiments. Animals were provided with standard chow (LabDiet 5053; LabDiet, Purina Mills) and maintained under a $12 \mathrm{~h}$ light/dark cycle. Animals were dark adapted overnight before experiments. All experiments were performed in accordance with the policy on the Use of Animals in Neuroscience Research and were approved by the Washington University Animal Studies Committee and the Medical University of South Carolina Animal Care and Use Committee.

Photopic visual acuity measured from optomotor responses. Visual acuity of 2-month-old mice was measured using a two-alternative, forcedchoice protocol (Umino et al., 2008), as described previously (Kolesnikov et al., 2010). Briefly, the Optomotry system (CerebralMechanics) consisted of a square array of four computer monitors and had a pedestal in the center where the mouse was placed. A television camera (Sony) was mounted above the animal to allow observation of the mouse but not the monitors. Rotating stimuli (sine wave vertical gratings of $100 \%$ contrast) were applied on the monitors, where they formed a virtual cylinder around the mouse (Prusky et al., 2004). The direction of the gratings movement for each $5 \mathrm{~s}$ trial was randomly selected by the computercontrolled protocol. Mice responded to the stimuli by reflexively rotating their head in the corresponding direction. The observer registered the direction of mouse head motion (clockwise or counterclockwise). Based on correctness of observer's responses and using the staircase paradigm, the computer protocol changed the spatial frequency $\left(F_{s}\right)$ of the stimuli, starting from 0.128 cycles per degree until reaching its threshold (visual acuity), defined as 70\% correct observer's responses (Umino et al., 2008). The speed of gratings $\left(S_{\mathrm{p}}\right)$ was set at its optimal value $\left(12.0^{\circ} / \mathrm{s}\right.$; adopted from Umino et al., 2008, and confirmed by us). Temporal frequency $\left(F_{\mathrm{t}}\right)$ was automatically adjusted by the computer program, based on the following equation: $F_{\mathrm{t}}=S_{\mathrm{p}} \cdot F_{\mathrm{s}}$. Optomotor responses were measured under either standard photopic conditions $\left(1.85 \log \mathrm{cd} \mathrm{m}^{-2}\right)$ or enhanced photopic conditions $\left(2.57 \log \mathrm{cd} \mathrm{m}^{-2}\right.$ ). Enhanced photopic conditions were achieved by using a white LED array mounted above the animal.

Antibodies. The rabbit anti-IRBP primary antibody was a generous gift from B. Wiggert (National Eye Institute, Bethesda, MD) and was used at a concentration of $1 \mu \mathrm{g} / \mathrm{ml}$ (Duncan et al., 2006). The peroxidase-labeled goat anti-rabbit IgG secondary antibody was from Vector Laboratories. $\beta$-Actin was imaged using a mouse anti- $\beta$-actin primary antibody
(Sigma) and a peroxidase-labeled goat anti-mouse IgG secondary antibody (Vector Laboratories). The anti-M/L-cone opsin antibody $(0.5 \mu \mathrm{g} /$ $\mathrm{ml})$ was from Millipore Bioscience Research Reagents. The anti-S-cone opsin antibody $(0.4 \mu \mathrm{g} / \mathrm{ml})$ was from Santa Cruz Biotechnology. Alexa488 secondary antibodies $(0.1 \mu \mathrm{g} / \mathrm{m})$ were from Invitrogen.

Cone density measurements. The right and left eyes from each animal were harvested for M/L- and S-opsin cone density measurements, respectively. After removing the cornea, the retina-lens complex was separated from the RPE-choroid layers and fixed in freshly prepared $4 \%$ paraformaldehyde in $0.1 \mathrm{M} \mathrm{PBS}$ at $\mathrm{pH} 7.4$ for $1.25 \mathrm{~h}$ at room temperature (RT). After gentle washing with PBS $(2 \times, 10 \mathrm{~min}, \mathrm{RT})$, retinas were incubated with appropriate primary antibodies overnight at $4^{\circ} \mathrm{C}$, washed with PBS $(2 \times, 10 \mathrm{~min}, \mathrm{RT})$ and then incubated with secondary antibodies for $2 \mathrm{~h}$ at RT. The retina-lens complex was washed with PBS $(2 \times, 10$ min, RT), and the lens was removed. Relaxing cuts were made to the retina, which was subsequently flatmounted onto a slide and coverslipped after application of Fluoromount-G (Southern Biotech). Samples were analyzed by fluorescence microscopy (Axioplan II, Zeiss) using a $100 \mathrm{~W}$ mercury light source with appropriate filters. Cones were manually counted within six fields of view, at $20 \times$ magnification that spanned the entire length of the retina dorsal-ventral axis. Cone densities were expressed as the number of cones per square millimeter.

Immunohistochemistry. After removing the cornea and lens, the remaining eyecup was fixed as described for preparation of tissue for cone density measurements. Eyecup was then washed $1 \times$ in PBS for $10 \mathrm{~min}$ and incubated in $30 \%$ sucrose buffered with PBS overnight at $4^{\circ} \mathrm{C}$. Next, the eyecup was embedded in Optimal Cutting Temperature compound (Ted Pella), flash frozen in 2-methylbutane (Sigma) on dry ice, and cut with a cryomicrotome to produce $8 \mu \mathrm{m}$ sections from the central region of the mouse eyecup immediately ventral to the optic nerve head. The sections were allowed to dry for $30 \mathrm{~min}$ at RT, gently washed in deionized water for $10 \mathrm{~min}$, dried again for $10 \mathrm{~min}$ at RT, and blocked for $1 \mathrm{~h}$ at RT with a solution containing $1 \%$ bovine serum albumin (Sigma), $1 \%$ donkey serum (Sigma), and 0.25\% Triton X-100 (Sigma) in PBS. Sections were then incubated overnight at $4^{\circ} \mathrm{C}$ with appropriate primary antibodies diluted in a solution containing 1\% Tween-20 (Bio-Rad) and 1\% Triton X-100 in PBS. Next, sections were washed once in PBS and then incubated with secondary antibodies diluted in PBS containing propidium iodide $(0.5 \mu \mathrm{g} / \mathrm{ml}$; Sigma) for $2 \mathrm{~h}$ at RT, washed with PBS $(2 \times, 10$ min, RT), and coverslip mounted with Fluoromount-G for analysis by confocal microscopy (TCS SP5 AOBS Confocal Microscope System, Leica). Images were acquired from the central region of the retina where the optic nerve head was visible.

Transretinal recordings from retinas and eyecups. Mice were killed by $\mathrm{CO}_{2}$ asphyxiation. For retina recordings, the whole retina was removed from eyecup under infrared illumination and was stored in oxygenated aqueous L15 (13.6 mg/ml, pH 7.4, Sigma) solution containing $0.1 \%$ BSA, at RT. For eyecup recordings, a piece of dorsal part of the eyecup (containing retina attached to the RPE and held in place with the optic nerve attachment on one side and small leftover of the cornea on the other side, with lens and vitreous removed) was gently cut (approximately one-third of whole eyecup) with microscissors and stored in the same solution. Retina or eyecup was mounted on filter paper with the photoreceptor side up (in the case of retina) or down (in the case of eyecup) and was placed on the recording chamber with an electrode connected to the bottom of the perfusion chamber. A second electrode was placed just above the center of retina/eyecup. The sample was perfused with Locke's solution containing $112.5 \mathrm{~mm} \mathrm{NaCl}, 3.6 \mathrm{~mm} \mathrm{KCl}, 2.4 \mathrm{~mm} \mathrm{MgCl}, 1.2 \mathrm{~mm}$ $\mathrm{CaCl}_{2}, 10$ mм HEPES, pH 7.2, 20 mм $\mathrm{NaHCO}_{3}, 3$ mм Na succinate, 0.5 mM Na glutamate, $0.02 \mathrm{~mm}$ EDTA, and $10 \mathrm{~mm}$ glucose. In addition, the solution was supplemented with $4 \mathrm{mM}$ DL-aspartate and $10 \mu \mathrm{M}$ DL-AP- 4 to block higher-order components of the photoresponse (Sillman et al., 1969), and with MEM vitamins and MEM amino acids solutions (Sigma) to improve retina/eyecup viability. The perfusion solution was continuously bubbled with $95 \% \mathrm{O}_{2} / 5 \% \mathrm{CO}_{2}$ mixture and heated to $36-37^{\circ} \mathrm{C}$. The electrode solution ( $140 \mathrm{~mm} \mathrm{NaCl}, 3.6 \mathrm{~mm} \mathrm{KCl}, 2.4 \mathrm{~mm} \mathrm{MgCl}_{2}, 1.2$ $\mathrm{mm} \mathrm{CaCl}$, 3 mM HEPES, 10 mm glucose, pH 7.4) in the lower electrode also contained $4 \mathrm{~mm}$ DL-aspartate and, in addition, $10 \mathrm{~mm} \mathrm{BaCl}_{2}$ to suppress the glial component of the photoresponse (Nymark et al., 2005). 
Light stimulation was applied by $20 \mathrm{~ms}$ test flashes of calibrated 505 nm LED light. For light uniformity, glass optical diffuser was placed between the LED and the preparation. The stimulating light intensity was controlled by computer in $0.5 \mathrm{log}$ unit steps. In experiments designed to monitor the recovery of cone a-wave flash sensitivity $\left(S_{\mathrm{f}}\right.$, see the definition below) after bleaching, $>90 \%$ of the cone visual pigment was bleached with a 3 s step of $505 \mathrm{~nm}$ light. The bleached fraction was estimated from the relation $F=1-\exp (-I P t)$, where $F$ is the fraction of pigment bleached, $t$ is the duration of the exposure to light (in seconds), $I$ is the bleaching light intensity of $505 \mathrm{~nm}$ LED light $\left(1.6 \times 10^{8}\right.$ photons $\mu \mathrm{m}^{-2} \mathrm{~s}^{-1}$ ), and $P$ is the photosensitivity of mouse cone at the wavelength of peak absorbance $\left(7.5 \times 10^{-9} \mu \mathrm{m}^{2}\right)$, adopted from Nikonov et al. (2006). Photoresponses were amplified by a differential amplifier (DP-311, Warner Instruments), low-pass filtered at $30 \mathrm{~Hz}$ (8-pole Bessel), digitized at $1 \mathrm{kHz}$, and stored on a computer for further analysis. Cone response kinetics were not adjusted for low-pass filtering. $S_{\mathrm{f}}$ was calculated from the linear region of the intensity-response curve as the ratio of cone a-wave response amplitude and flash strength. Halfsaturating light intensity $\left(I_{1 / 2}\right)$ was calculated from the intensity-response relation as the test flash intensity required to produce a response with an amplitude equal to half of the corresponding saturated response amplitude. The time constant of the dim flash response recovery $\left(\tau_{\text {rec }}\right)$ was derived from single-exponential fit to the falling phase of the response. Data were analyzed using Clampfit 10.2 and Origin 8.1 software.

Electroretinography. Dark-adapted mice were anesthetized with a subcutaneous injection of a mixture of ketamine $(100 \mathrm{mg} / \mathrm{kg})$ and xylazine (20 mg/kg). Pupils were dilated with $1 \%$ atropine sulfate. Mouse body temperature was maintained at $37^{\circ} \mathrm{C}$ with a passive-heating pad. ERG responses were measured from both eyes using contact corneal platinum-ring electrodes held in place by a drop of Gonak solution. Full-field ERGs were recorded with the UTAS-E 3000 system (LKC Technologies), using 15-650 $\mu$ s Ganzfeld-derived stimuli of calibrated Xenon Flash tube white light with maximum intensities of $470 \mathrm{~cd} \mathrm{~m}^{-2}(2.7 \mathrm{log}$ $\mathrm{cd} \mathrm{m}^{-2}$ ) for test flashes and $514 \mathrm{~cd} \mathrm{~m}^{-2}$ for background light. In the case of Irbp ${ }^{+/+} \mathrm{T} \alpha^{-/-}$and Irbp ${ }^{-/-} \mathrm{T} \alpha^{-/-}$mice, cone b-wave flash sensitivity $\left(S_{\mathrm{f}}\right.$, calculated from the linear region of the intensity-response curve as the ratio of cone b-wave response amplitude and flash strength) was first determined in darkness (up to 20 measurements were averaged). Then, bright white background Ganzfeld illumination $\left(514 \mathrm{~cd} \mathrm{~m}^{-2}\right)$ was applied continuously for $15 \mathrm{~min}$ while cone b-wave $S_{\mathrm{f}}$ change was monitored. At the end of this light adaptation period, mice were reanesthetized one time with a smaller dose of ketamine (approximately one-half of the initial dose), eyes were dilated again with a drop of $1 \%$ atropine sulfate, and a 1:1 mixture of PBS and Gonak solutions was gently applied to the eyes using a plastic syringe to protect them from drying and to maintain electrode contacts. Finally, $>90 \%$ of cone pigment was bleached by a $30 \mathrm{~s}$ exposure to bright light delivered by $520 \mathrm{~nm}$ LED focused at the surface of mouse eye cornea and producing $\sim 1.3 \times 10^{8}$ photons $\mu \mathrm{m}^{-2} \mathrm{~s}^{-1}$. The bleaching fraction was estimated using the relation $F=1-\exp (-I P t)$, defined in the previous paragraph. After the bleach, the recovery of cone b-wave flash sensitivity was followed in darkness.

For rod experiments, the recovery of scotopic (rod-driven) ERG a-wave amplitude and flash sensitivity $\left(S_{\mathrm{f}}\right.$, calculated from the linear region of the intensity-response curve as the ratio of rod a-wave response amplitude and flash strength) following a bleach were monitored for the following mouse strains: C57BL/6, original $\mathrm{Irbp}^{-1-}$ (C57BL/6 background), 129S2/Sv, and $\operatorname{Irbp}^{-/-}$(129S2/Sv background). Anesthesia and atropine/PBS/Gonak solution were applied every 30-40 min during the $2 \mathrm{~h}$ testing time.

Western blots. To determine whether the perfusion of $\operatorname{Irbp}{ }^{+/+} \mathrm{T}^{-/-}$ eyecups altered endogenous levels of IRBP during typical recording sessions, IRBP levels after 30 min of perfusion were analyzed. Control and perfused eyecups were homogenized in $1 \%$ SDS in $1 \times$ PBS buffer, $\mathrm{pH}$ 7.4, containing Mini Protease Inhibitor (Roche; 1 tablet per $10 \mathrm{ml}$ solution), and equivalent amounts of total protein $(20 \mu \mathrm{g})$ were loaded onto $12 \%$ polyacrylamide gels following the XCell II Blot Module protocol (Invitrogen). The primary antibody $(1: 10,000)$ for IRBP detection was the rabbit anti-IRBP antibody. The secondary antibody (1:2000) was goat

\section{Table 1. Photopic visual acuity in various mouse strains}

\begin{tabular}{|c|c|c|c|c|}
\hline Mouse strains & $1.85 \log c \mathrm{~d} \mathrm{~m}^{-2}$ & $2.57 \log c d m^{-2}$ & $p_{2}$ & RPE65 variant \\
\hline$I r b p^{+/+} T \alpha^{-/-}(n=5)$ & $0.71 \pm 0.01$ & $0.80 \pm 0.02$ & 0.002 & \\
\hline $1 r b p^{-/-} T \alpha^{-/-}(n=5)$ & $0.66 \pm 0.02$ & $0.69 \pm 0.02$ & 0.22 & Leu450 \\
\hline$p_{1}$ & 0.041 & 0.003 & & \\
\hline $12952 / \mathrm{Sv}(n=5)$ & $0.74 \pm 0.01$ & $0.78 \pm 0.01$ & 0.04 & \\
\hline $1 \mathrm{rbp}^{-1-}[129 \mathrm{~S} 2 / \mathrm{Sv}](n=5)$ & $0.66 \pm 0.03$ & $0.69 \pm 0.02$ & 0.41 & Leu450 \\
\hline$p_{1}$ & 0.019 & 0.007 & & \\
\hline $\mathrm{C} 57 \mathrm{BI} / 6(n=5)$ & $0.74 \pm 0.02$ & $0.82 \pm 0.02$ & 0.02 & \\
\hline $\mid \mathrm{rbp}^{-/-}[\mathrm{C} 57 \mathrm{~B} \mid / 6](n=3)$ & $0.71 \pm 0.03$ & $0.78 \pm 0.02$ & 0.15 & Met450 \\
\hline$p_{1}$ & 0.50 & 0.24 & & \\
\hline
\end{tabular}

Values are given in cycles per degree. Data were derived from mouse optomotor responses to rotating gratings under two photopic background illumination conditions ( 1.85 or $\left.2.57 \log \mathrm{cd} \mathrm{m}^{-2}\right)$. Values are means \pm SEM. Significance levels: $p_{1}$ values indicate comparisons between specified pairs of mouse strains (within the same background light intensity); and $p_{2}$ values indicate comparisons within the same mouse strain (between two different illumination conditions).

anti-rabbit IgG (Vector Laboratories). $\beta$-actin served as a loading control using mouse anti- $\beta$-actin (1:2000; Sigma) as a primary antibody and a goat anti-mouse IgG (1:5000; Vector Laboratories) secondary antibody. Blots were visualized with SuperSignal West Dura Extended Duration Substrate (Thermo Scientific). Images were captured on a VersaDoc Imaging System (Bio-Rad), and densitometry was performed using imaging analysis software (ImageJ $1.40 \mathrm{~g}$ ).

Statistics. For all experiments, data were expressed as mean \pm SEM. Data were analyzed using independent two-tailed Student's $t$ test, with an accepted significance level of $p<0.05$.

\section{Results}

\section{Photopic visual function in IRBP-deficient mice}

To characterize the cone visual function in IRBP-deficient mice, we initially performed behavioral tests based on the ability of mice to reflexively track computer-generated rotating sine-wave gratings (Prusky et al., 2004). The optomotor response thresholds for spatial frequency of the stimuli (visual acuity) were measured under two different photopic background light intensities ( 1.85 or $2.57 \log \mathrm{cd} \mathrm{m}^{-2}$ ) in six various mouse lines with either normal IRBP levels or lacking the endogenous IRBP. Four of these lines $\left(\operatorname{Irb} p^{+/+} T \alpha^{-1-}\right.$ and $\operatorname{Irb} p^{-/-} T \alpha^{-1-}$ mice, as well as 129S2/Sv strain and Irbp ${ }^{-/-}$mice on the 129S2/Sv background) were homozygous for the Leu450 allele of Rpe65 gene, thus expressing RPE65 protein with high retinoid isomerase activity. The other two lines (C57BL/6 strain and $\mathrm{Irbp}^{-1-}$ mice on the C57BL/6 background) expressed the Met450 variant of RPE65, which has substantially reduced $(\sim 70 \%)$ isomerase activity (Redmond et al., 2007) and slower rhodopsin regeneration (Wenzel et al., 2001).

We found that under standard photopic conditions (1.85 log $\mathrm{cd} \mathrm{m}^{-2}$ ) visual acuity of the two IRBP-deficient mouse lines having Leu450 variant of RPE65 ( $\operatorname{rrb} p^{-/-} \mathrm{T} \alpha^{-/-}$mice and Irbp ${ }^{-/-}$ mice on the $129 \mathrm{~S} 2 / \mathrm{Sv}$ background) was slightly lower (7-11\%) compared with the corresponding control strains (Table $1, p_{1}$ values). Deletion of IRBP had no effect on the visual contrast sensitivity of these animals (data not shown). Interestingly, the visual acuity in $\operatorname{Irbp} p^{-1-}$ mice on the C57BL/6 background expressing the Met450 isoform of RPE65 was unchanged (Table 1). In an attempt to reveal any further detrimental effect of the lack of IRBP on cone-mediated vision, we increased the intensity of background light during the behavioral task (approximately fivefold) by using a white LED array mounted above the animal. Under these enhanced photopic conditions $\left(2.57 \log \mathrm{cd} \mathrm{m}^{-2}\right)$, all control strains exhibited a $5-11 \%$ increase in their visual acuity compared with standard photopic conditions (Table $1, p_{2}$ values), presumably due to cone response acceleration during light adaptation (Nikonov et al., 2006), which could potentially 
A

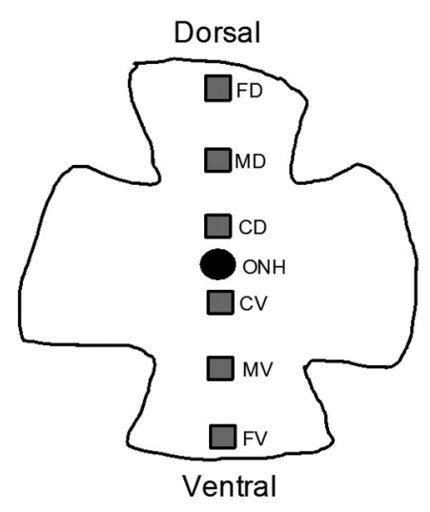

$\mathrm{B}$

B M/L-opsin
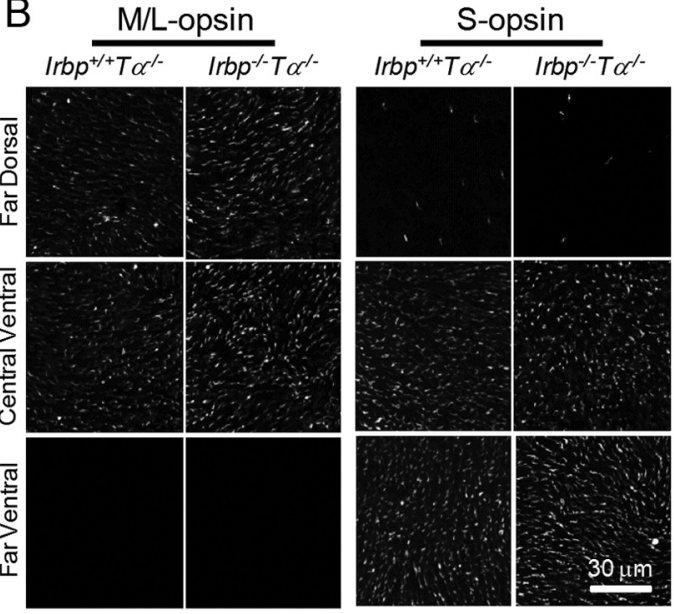

C

$\underline{\text { M/L-cones }}$

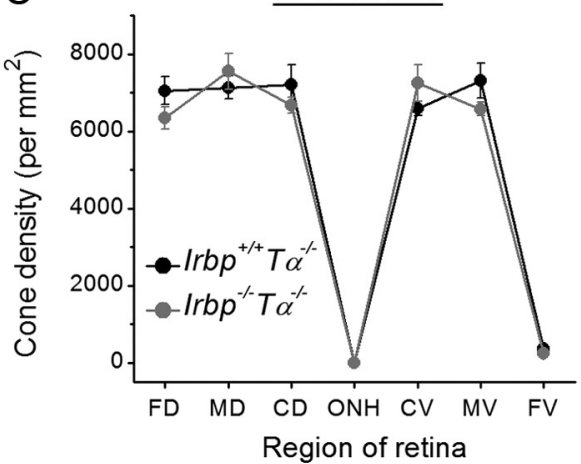

$\underline{\text { S-cones }}$

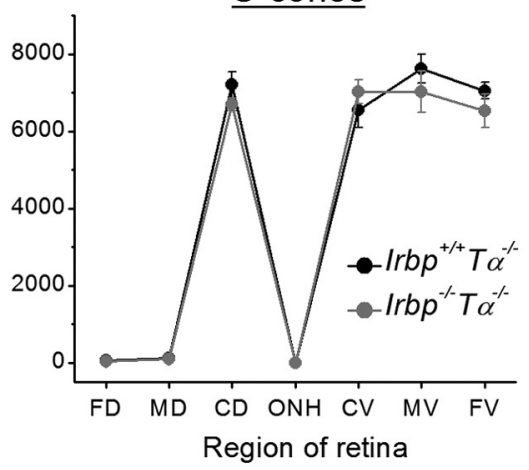

Figure 1. Cone densities in 2-month-old $/ r b p^{-1-} T \alpha^{-1-}$ mice. $A$, Schematic representation of retinal flatmount with the six regions analyzed for cone density spanning the dorsal-ventral axis. FD, Far-dorsal; $M D$, mid-dorsal; $C D$, central-dorsal; $0 \mathrm{NH}$, optic nerve head; $\mathrm{CV}$, central-ventral; MV, mid-ventral; FV, far-ventral. $\boldsymbol{B}$, Images of flatmounted retinas stained with M/L- (left) or S(right) cone opsins. Scale bar, $30 \mu \mathrm{m}$. C, No differences in M/L- (left) or S- (right) cone densities are observed between retinas of $I r b p^{+/+} T \alpha^{-/-}(n=4)$ and $I r b p^{-1-} T \alpha^{-/-}(n=4)$ mice. Values are means \pm SEM. The $p$ values are $>0.05$ for all retina locations in all panels.

improve the spatiotemporal resolution of photopic vision. In contrast, the visual acuity of all IRBP-deficient strains was unchanged. This further increased the difference in visual acuity between control and IRBP-deficient mice with Leu450 variant of RPE65 to $12-13 \%$ but kept the visual acuity of $I r b p^{-/-}$mice on the Met450 RPE65 background (C57BL/6) comparable to that of controls $\left(p_{1}=0.24\right)$. Thus, the deletion of IRBP resulted in slightly reduced photopic vision in mice expressing the Leu450 isoform of RPE65 but not in those expressing Met450 RPE65.

Normal cone density and proper cone pigment localization in Ir $b \boldsymbol{p}^{-/-} \boldsymbol{T} \boldsymbol{\alpha}^{-/-}$mice

To test whether the minor change in photopic visual acuity in $\operatorname{Irbp} p^{-1}$

${ }^{-} \mathrm{T} \alpha^{-/-}$mice was caused by possible mild degeneration of cones, we quantified cone densities by counting immunostained $\mathrm{M} / \mathrm{L}-$ and $\mathrm{S}$-cones in six areas from the dorsal-to-ventral retina (Fig. $1 A$ ). M/Lcones were present in all studied retina regions (from far-dorsal to mid-ventral) with the exception of the far-ventral region (Fig. $1 B$, left). In contrast, S-cones were abundant in all ventral regions of the retina but virtually absent in the far- and mid-dorsal retina areas (Fig. $1 B$, right). Such localization of both mouse cone types is consistent with that described previously (Applebury et al., 2000). At all retina locations, we observed no differences in $\mathrm{M} / \mathrm{L}$-cone (Fig. $1 C$, left) or S-cone (Fig. $1 C$, right) densities between retinas from 2-month-old Irbp ${ }^{+/+} T \alpha^{-1-}$ and $\operatorname{Irb} p^{-1-} T \alpha^{-/-}$mice $(p>0.05$ for all retina parts). Quantified cone densities were similar to those in wild-type mouse retinas found in previous studies (Zhang et al., 2008; Tang et al., 2010). On the other hand, rods were moderately degenerated in 2-month-old Irbp ${ }^{-1-} T \alpha^{-1-}$ animals, as evidenced by the reduction in the number of their nuclei in the ONL (Fig. $2 A$, right), consistent with earlier reports on $\operatorname{Ir} b p^{-/-}$mice (Liou et al., 1998; Ripps et al., 2000; Jin et al., 2009).

To test for possible opsin mislocalization, we analyzed the distribution of $\mathrm{M} / \mathrm{L}$ and S-cone opsins in $\operatorname{Irbp}{ }^{+/+} T \alpha^{-/-}$and Irbp ${ }^{-/-} T \alpha^{-I-}$ mouse cones by immunohistochemistry on retina cross sections. In both mouse lines, $\mathrm{M} / \mathrm{L}$ - and S-cone opsins were localized exclusively in cone outer segments (Fig. 2A). As expected, immunostaining of $\operatorname{Irbp} p^{-/-} T \alpha^{-/-}$retinas with anti-IRBP antibody yielded negative results (Fig. 2B). Together, the normal cone density and proper cone pigment localization indicate the absence of detectable cone degeneration in $\mathrm{Irbp}^{-1-}$ $T \alpha^{-/-}$mice. Thus, the slightly lower photopic visual acuity in IRBP-deficient mice was unlikely to be due to morphological defects in their cones and most likely reflected functional changes induced upon the deletion of IRBP.

\section{Altered M/L-cone photoresponses in IRBP-deficient mice}

To investigate further the possible reason for the slightly reduced photopic visual acuity in IRBP-deficient mice and to directly examine how the deletion of IRBP affects cone photoresponses, we recorded families of cone transretinal responses to test flashes of increasing light intensities either from isolated $I r b p^{+/+} T \alpha^{-/-}$and $I r b p^{-/-} T \alpha^{-/-}$mouse retinas or from intact eyecups with retina attached to the RPE (Fig. 3). Both strains expressed the more efficient Leu450 isoform of RPE65. The lack of rod transducing $\alpha$-subunit in these mice completely eliminated the interfering rod signaling (Calvert et al., 2000). Eyecup recordings were initially hampered by rapid detachment of the mouse retina from the RPE, especially under perfusion with physiological solution. We were able to circumvent this issue by recording from a section of eyecup with the retina held in place by the optic nerve attachment on one side and by a small leftover of the cornea on the other side. We found that the maximal M/L-cone response amplitude was, on average, $\sim 2$ times larger in control retinas (Fig. $3 A$ ) and $\sim 1.4$ times larger in control eyecups (Fig. 3B) compared with those from IRBPdeficient animals. In addition, cone photoresponses from eyecups were typically several times smaller than those from isolated retinas in both mouse lines, likely due to increased resistance between the recording electrodes in samples including the sclerachoroid complex and RPE in addition to the retina as well as to the presence of part of the optic nerve head on the edge of preparation. The half-saturating light intensity for $\operatorname{Irbp}^{-/-} \mathrm{T} \alpha^{-\prime-}$ mouse cones was decreased by a factor of $\sim 2.3(p<0.05)$ in retinas (Fig. $4 A$ ) and by $\sim 1.9$-fold $(p<0.05$ ) in eyecups (Fig. 


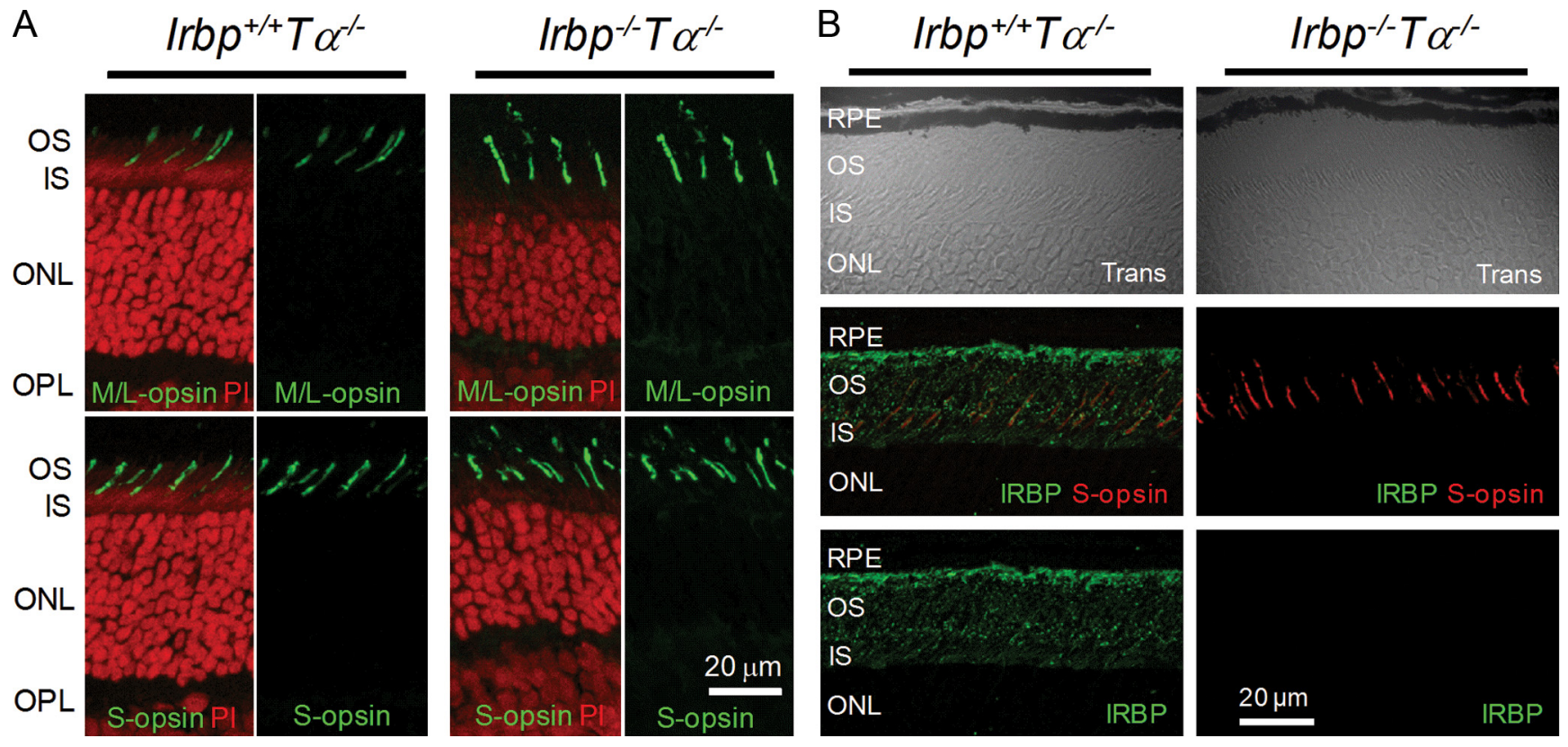

Figure 2. Cone opsin localization in 2-month-old Irbp ${ }^{-/-} T \alpha^{-/-}$mice. A, Both M/L- and S-opsins are localized in cone outer segments of $/ r b p^{+/+} T \alpha^{-/-}$and Irbp ${ }^{-/-} T \alpha^{-/-}$mice. Cross-section images of the retina (central-ventral location to the optic nerve head) are shown. OS, Outer segments; IS, inner segments; ONL, outer nuclear layer; OPL, outer plexiform layer. Scale bar, $20 \mu \mathrm{m}$. Cell nuclei were stained with propidium iodide (PI). B, Immunostaining of $/ r b p^{+/+} T \alpha^{-1-}$ and $/ r b p^{-/-} T \alpha^{-/-}$retinas (central-ventral retina location) with anti-IRBP antibody. Trans, Confocal images in transmitted light. Scale bars, $20 \mu \mathrm{m}$.
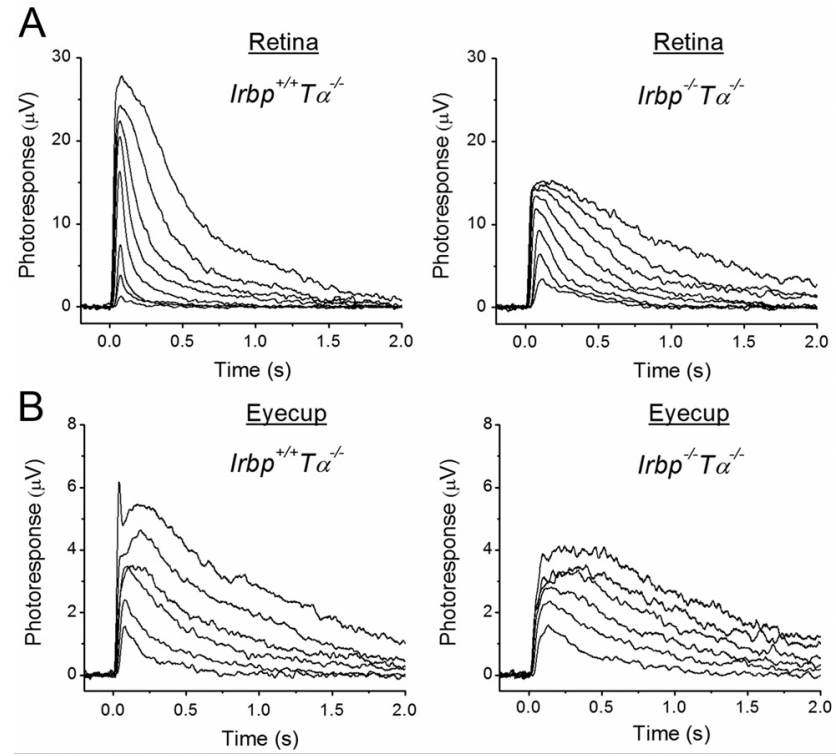

Figure 3. $\quad \boldsymbol{A}, \boldsymbol{B}$, Families of isolated retina $(\boldsymbol{A})$ and eyecup $(\boldsymbol{B}) \mathrm{M} / \mathrm{L}$-cone transretinal responses from 1- to 2-month-old $/ r b p^{+/+} T \alpha^{-/-}$and $/ r b p^{-/-} T \alpha^{-/-}$mice. $A$, Responses from representative retinas. Flash strengths increased from $2.2 \times 10^{3}$ to $5.5 \times 10^{6}$ photons $\mu \mathrm{m}^{-2}$, with a step of $\sim 0.5 \log$ units ( $505 \mathrm{~nm}$ light). Photoreceptors faced up to the stimulating light. $\boldsymbol{B}$, Population-averaged traces (from 7 eyecups in each case). Flash strengths increased from $1.7 \times 10^{4}$ to $5.5 \times 10^{6}$ photons $\mu \mathrm{m}^{-2}$, with a step of $\sim 0.5 \log$ units $(505 \mathrm{~nm}$ light). Photoreceptors faced down from the stimulating light.

$4 B$ ) compared with $\operatorname{Irb} p^{+/+} T \alpha^{-/-}$preparations (see Fig. 4 legend for $I_{1 / 2}$ values), indicating a corresponding increase in cone sensitivity. A possible explanation for this apparent sensitization could be the retarded inactivation of $\operatorname{Irbp}{ }^{-/-} T \alpha^{-/-}$cone photoresponses as their shutoff in both retinas (Fig. 4C) and eyecups (Fig. $4 D$ ) was, on average, $\sim 1.7$ times slower in mutant mice. $\tau_{\text {rec }}$ values determined from single-exponential fits to the falling
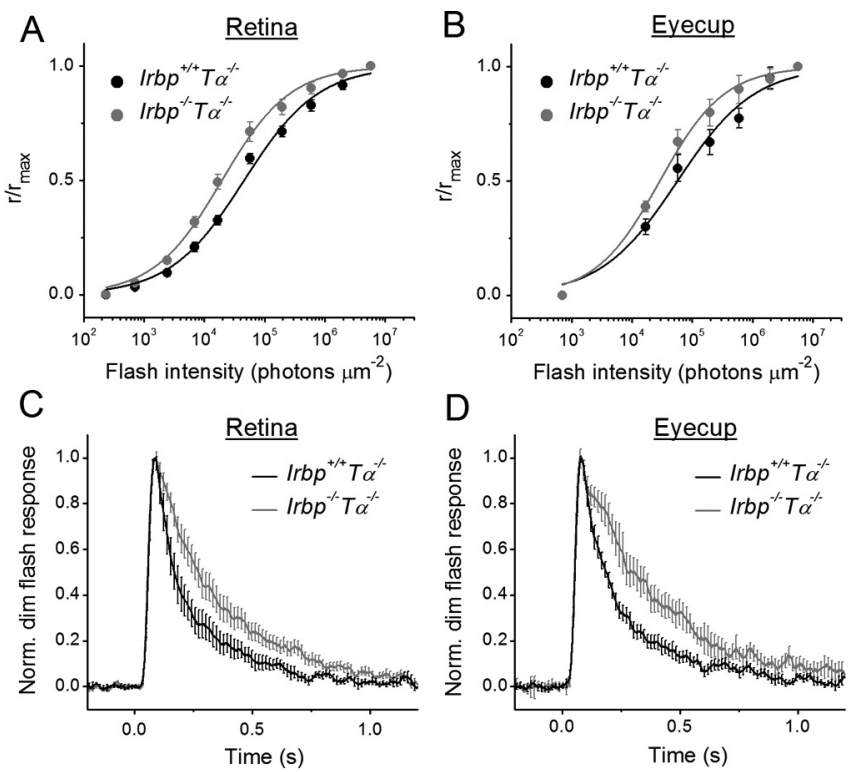

Figure 4. Sensitivity $\left(I_{1 / 2}\right)$ and kinetics of $\mathrm{M} / \mathrm{L}$-cone photoresponses in $/ r b p^{-/-} T \alpha^{-/-}$ mice. $\boldsymbol{A}, \boldsymbol{B}$, Normalized averaged intensity-response relations of isolated retinas $(\boldsymbol{A})$ and eyecups (B). Points were fitted with Naka-Rushton hyperbolic functions, as follows:

$$
\frac{R}{R_{\max }}=\frac{I^{n}}{I^{n}+I_{1 / 2}^{n}},
$$

where $R$ is the transient-peak amplitude of response, $R_{\max }$ is the maximal response amplitude I is the flash intensity, $n$ is the Hill coefficient (exponent). $A$, Retinas: Irbp ${ }^{+/+} T \alpha^{-/-}(n=13)$, Irbp ${ }^{-1-} T_{\alpha}{ }^{-\prime-}(n=11)$. Half-saturated intensities $\left(I_{1 / 2}\right)$ were $4.5 \times 10^{4}$ and $2.0 \times 10^{4}$ photons $\mu \mathrm{m}^{-2}$, and exponents were 0.71 and 0.77 , respectively. $B$, Eyecups: Irbp ${ }^{+/+}$ $T \alpha^{-1-}(n=7), I r b p^{-1-} T \alpha^{-1-}(n=7)$. Half-saturating intensities were $5.5 \times 10^{4}$ and $2.9 \times 10^{4}$ photons $\mu \mathrm{m}^{-2}$, and exponents were 0.69 and 0.80 , respectively. C, $\boldsymbol{D}$, Populationaveraged normalized responses to $1.7 \times 10^{4}$ photons $\mu \mathrm{m}^{-2}$ test stimuli. Error bars represent SEM. C, Retinas: $\operatorname{Irbp}^{+/+} T \alpha^{-/-}(n=7), I r b p^{-/-} T \alpha^{-/-}(n=12)$. D, Eyecups: Irbp $p^{+/+}$ $T \alpha^{-\prime-}(n=18), I r b p^{-1-} T \alpha^{-\prime-}(n=16) . \tau_{\text {rec }}$ determined from single-exponential fits (data not shown) were $\sim 180 \mathrm{~ms}\left(\mathrm{Irbp}^{+/+} T \alpha^{-/-}\right.$) and $300 \mathrm{~ms}\left(\mathrm{lrbp}{ }^{-/-} T \alpha^{-/-}\right.$), respectively. 
phase of photoresponse were $\sim 180 \mathrm{~ms}\left(\mathrm{Irbp}^{+/+} \mathrm{T \alpha}^{-/-}\right)$and $\sim 300 \mathrm{~ms}\left(\mathrm{Irbp}^{-1-} \mathrm{T \alpha}^{-/-}\right)$in both retinas and eyecups. The time-to-peak of our cone dim flash responses $(77-85 \mathrm{~ms}$ in both Irbp ${ }^{+/+} T \alpha^{-/-}$and Irbp ${ }^{-/-} T \alpha^{-/-}$animals) was comparable to previously published results (Nikonov et al., 2006; Wang and Kefalov, 2009). However, the $\tau_{\text {rec }}$ in our $I r b p^{+/+} \mathrm{T \alpha}^{-/-}$mice was slower than published values, perhaps due to a gradual genetic shift in the mice in our colony.

The reason for the smaller response amplitude and slower inactivation of phototransduction cascade in cones from mice lacking IRBP is unclear. Although normal cone densities and proper localization of pigment in cone outer segments rule out degeneration as a cause for altered photoresponse in cones of mutant mice, there is still the possibility of abnormal expression or localization of some phototransduction proteins in the cones of our Irbp ${ }^{-1-} \mathrm{T}^{-1-}$ mice. The smaller and slower cone responses in darkness likely were the cause for the slightly reduced photopic visual acuity in IRBP-deficient mice. Notably, however, cone function in $\operatorname{Irbp} \mathrm{p}^{-/-} \mathrm{T} \alpha^{-/-}$mice was still robust and allowed us next to investigate the role of IRBP in cone pigment regeneration.

M/L-cone dark adaptation in control and IRBP-deficient mice We directly addressed the possible role of IRBP in cone dark adaptation in intact $I r b p^{+/+} \mathrm{T}^{-/-}$and $I r b p^{-1-} T \alpha^{-/-}$retinas and eyecups, by tracing the recovery of M/L-cone a-wave flash sensitivity after almost complete (>90\%) bleaching of cone visual pigment (Fig. 5). For proper interpretation of the transretinal recording results, we performed two preceding control experiments. First, we sought to establish that the level of endogenous IRBP in our $I r b p^{+/+} \mathrm{T}^{-/-}$eyecup preparations was not decreased due to washing out by perfusion during up to $30 \mathrm{~min}$ recording sessions. By using Western blot analysis, we confirmed the lack of IRBP loss to the superfusate in control $\mathrm{Irbp}^{+/+} \mathrm{T \alpha}^{-/-}$ eyecups (Fig. $5 A, B$ ). Second, we determined that the flash sensitivity of dark-adapted retinas was stable during 30 min experiments (reduced by not $>10 \%$ ), as shown by the top traces in Figure 5, $C$ and $D$. This was also the case in eyecup preparations, which are less disturbed by the dissection (data not shown). Thus, our preparations did not lose IRBP and were stable during the transretinal recordings.

We then investigated how the deletion of IRBP affects cone pigment regeneration through the retina visual cycle (using isolated retina recordings) (Fig. $5 C$ ) or through the combined actions of the retina and RPE visual cycles (using eyecup recordings) (Fig. 5D). Surprisingly, the kinetics of cone photosensitivity recovery after bleaching $>90 \%$ of pigment, which produced substantial initial desensitization, was identical in $\operatorname{Irbp}{ }^{+/+} \mathrm{T \alpha}^{-/-}$ and $I r b p^{-1-} / T \alpha^{-1-}$ mice. Thus, the deletion of IRBP did not cause detectable impairment of 11-cis-retinal recycling through both retina and RPE visual cycles for M/L-cone visual pigment regeneration.

Notably, in both mouse lines recovery of cone a-wave flash sensitivity in eyecups was biphasic, with a rapid phase similar to the single recovery phase observed in isolated retinas (time constants of $\sim 1.2$ and $1.7 \mathrm{~min}$, respectively) (Fig. $5 \mathrm{C}$ ) followed by a slower phase (time constants of $\sim 13$ and $10 \mathrm{~min}$, correspondingly) driven by the RPE (Fig. 5D). This result demonstrates that the retina visual cycle promotes cone dark adaptation approximately eightfold faster than the canonical RPE visual cycle. The final relative level of photosensitivity recovery in eyecups was, on average, approximately two times higher compared with that in isolated retinas ( $60 \mathrm{vs} 34 \%$ by $30 \mathrm{~min}$ after bleaching, cor-
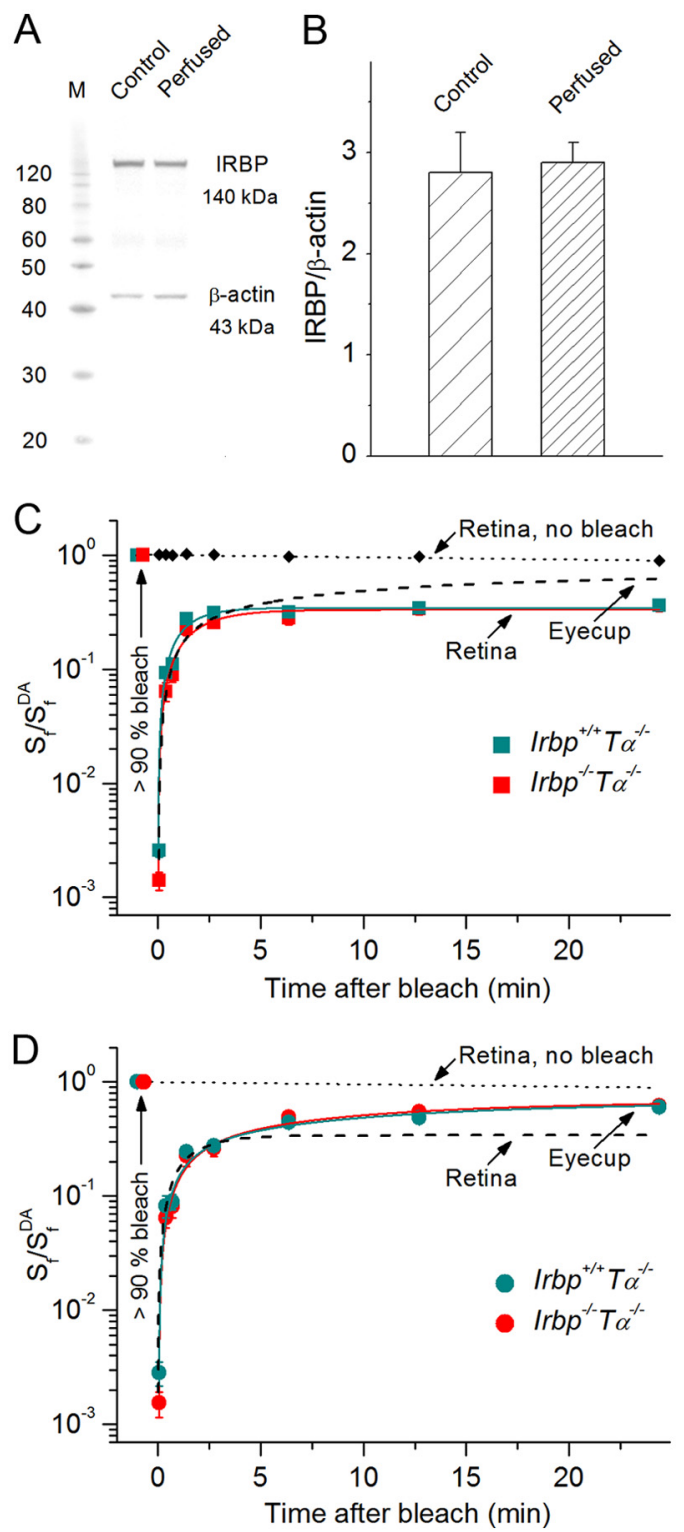

Figure 5. M/L-cone dark adaptation in $/ r b p^{-/-} T \alpha^{-/-}$mice. A, Representative Western blot of $/ r b p^{+/+} T \alpha^{-/-}$eyecup before and after 30 min perfusion to determine levels of endogenous IRBP. $\beta$-actin served as a loading control. Both IRBP and $\beta$-actin amounts were within the linear range of the Western blot sensitivity (data not shown). $\boldsymbol{B}$, Quantification of the data shown in $\boldsymbol{A}(n=4)$. Values are means \pm SEM. $\boldsymbol{C}, \boldsymbol{D}$, Recovery of cone a-wave flash sensitivity $\left(S_{f}\right)$ in mouse retinas $(\boldsymbol{C})$ and eyecups $(\boldsymbol{D})$ after bleaching $>90 \%$ of cone pigment at time 0 (with $505 \mathrm{~nm}$ LED light). Retinas: $\mathrm{Irbp}^{+/+} T \alpha^{-/-}(n=9), / \mathrm{rrpp}^{-/-} T \alpha^{-\prime-}(n=7)$. Eyecups: $I r b p^{+/+} T \alpha^{-/-}(n=11), \operatorname{Irbp}{ }^{-1-} T \alpha^{-/-}(n=8)$. C, Retina data were fitted with single-exponential functions that yielded time constants of $\sim 1.2$ and $\sim 1.7 \mathrm{~min}$, respectively. $\boldsymbol{D}$, Eyecup data were then fitted with double-exponential functions, and their initial rapid phase was fitted using the same time constants as determined for retinas (fixed parameter). $R^{2}=$ 0.98. The slow RPE-driven cone recovery time constants for $I r b p^{+/+} T \alpha^{-/-}$and $I r b p^{-/-}$ $T \alpha^{-1-}$ animals were $\sim 13$ and $\sim 10 \mathrm{~min}$, correspondingly. Values are means $\pm \mathrm{SEM}$. $\mathrm{S}_{\mathrm{f}}^{\mathrm{DA}}$ indicates sensitivity of dark-adapted preparations. Dashed lines show the cone a-wave flash sensitivity recovery (averaged data from the two mouse lines) in eyecups $(\boldsymbol{C})$ and retinas (D), for comparison. Small black symbols connected with the dotted line $(\boldsymbol{C})$ or the dotted line alone (D) show the stable flash sensitivity of dark-adapted retina during the 30 min recording session (combined data from $/ r b p^{+/+} T \alpha^{-/-}$and $/ r b p^{-/-} T \alpha^{-/-}$retinas, $n=8$ ).

respondingly). Importantly, in our best eyecup preparations it reached $\sim 100 \%$ in both mouse lines (data not shown), indicating that the action of the retina visual cycle alone is not sufficient and that chromophore delivered from both visual 

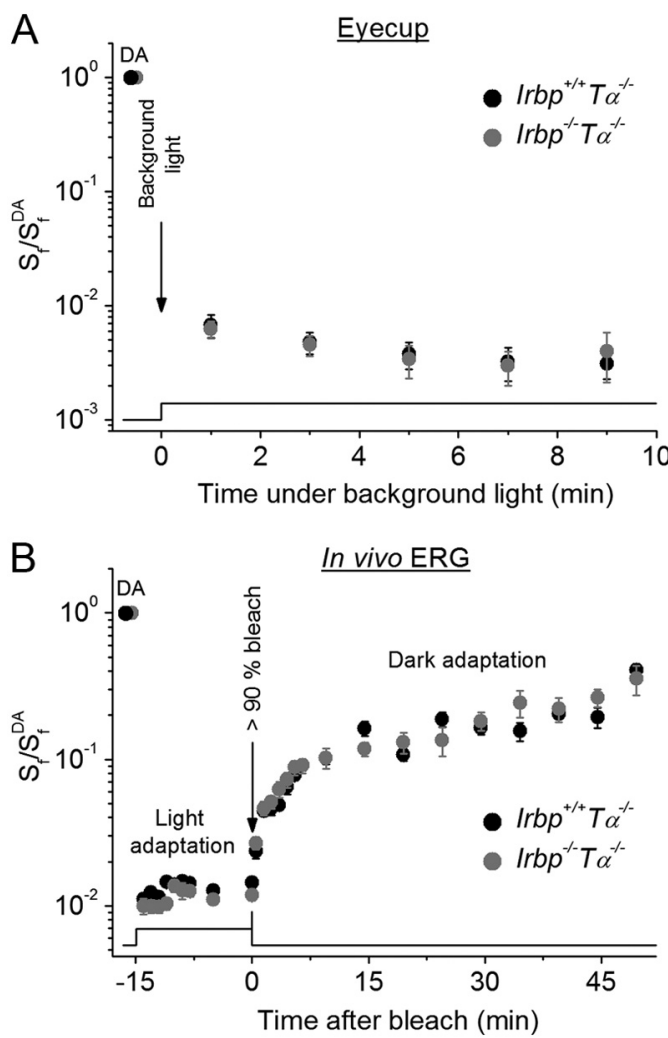

Figure 6. M/L-cone light adaptation in $/ \mathrm{rbp}{ }^{-/-} T \alpha^{-1-}$ mice. $A$, Change of eyecup cone a-wave $S_{\mathrm{f}}$ (after applying constant background $505 \mathrm{~nm}$ LED light $\left(2.9 \times 10^{6}\right.$ photons $\mu \mathrm{m}^{-2}$ $\left.\mathrm{s}^{-1}\right) \cdot \mathrm{Irbp}^{+/+} T \alpha^{-/-}(n=9), \mathrm{Irbp}^{-1-} T \alpha^{-{ }^{--}}(n=9)$. Values are means \pm SEM (smaller than symbol size for most data points). $S_{\mathrm{f}}{ }^{\mathrm{DA}}$ indicates flash sensitivity of dark-adapted eyecups.

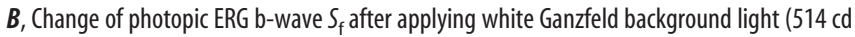
$\mathrm{m}^{-2}, 15 \mathrm{~min}$ ) and its subsequent recovery (in darkness) after bleaching $>90 \%$ of cone pigment. Live animals: Irbp ${ }^{+/+} T \alpha^{-/-}$( $n=5$ mice), $I r b p^{-/-} T \alpha^{-\prime-}(n=5$ mice). Flash sensitivity was normalized to its dark-adapted value $\left(S_{f}{ }^{\text {DA }}\right)$. Bleaching was achieved by $30 \mathrm{~s}$ illumination with $520 \mathrm{~nm}$ LED light at time 0 . Values are means \pm SEM. The time course of light stimulation in $\boldsymbol{A}$ and $\boldsymbol{B}$ is shown on the bottom.

cycles is required for complete $\mathrm{M} / \mathrm{L}$-cone pigment regeneration to prebleach levels.

\section{Normal M/L-cone light adaptation in IRBP-deficient mice}

To investigate further the possible role of IRBP in cone pigment regeneration, we monitored the change in $\mathrm{M} / \mathrm{L}$-cone photosensitivity $\left(S_{\mathrm{f}}\right)$ in eyecup preparations after applying bright background light that would continuously bleach the cone pigment at a high rate. Initially, this background light quickly desensitized cones by $>2 \log$ units, followed by another approximately threefold slower desensitization during $10 \mathrm{~min}$ of steady illumination (Fig. 6A). Notably, relative desensitization levels in $\operatorname{Irb} p^{+/+} T \alpha^{-/-}$and $\operatorname{Irb} p^{-/-} T \alpha^{-/-}$ eyecups during this light adaptation period were indistinguishable, indicating that the rate of cone pigment regeneration was unaffected by the deletion of IRBP. This result is consistent with the unaltered kinetics of cone a-wave flash sensitivity recovery in the absence of IRBP (Fig. 5C,D). Thus, endogenous IRBP does not appear to accelerate $\mathrm{M} / \mathrm{L}$-cone pigment regeneration for maintaining adequate mouse cone sensitivity under photopic conditions.

The most native conditions for physiological experiments are obviously those where live animals are used. Therefore, finally we tested the effect of IRBP deletion on the change of photosensitiv- ity during light and dark adaptation of cones in live $\operatorname{Irbp} \mathrm{p}^{+/+}$ $T \alpha^{-/-}$and Irbp ${ }^{-/-} T \alpha^{-/-}$mice, by performing in vivo full-field ERG recordings. Due to the very small amplitude of the photopic a-wave in the mouse that is masked by a large cone bipolar celldriven b-wave of the opposite polarity, we used cone b-waves to monitor cone sensitivity. After recording the dark-adapted cone b-wave flash sensitivity, a bright white Ganzfeld light was turned on to immediately induce a $2 \log$ units cone desensitization (Fig. $6 B)$. During an initial 15 min light adaptation period, we observed no difference in cone b-wave flash sensitivity change between $\operatorname{Irb} p^{+/+} T \alpha^{-/-}$and $\operatorname{Irbp} p^{-/-} T \alpha^{-/-}$animals. In both cases, there was a small initial increase of b-wave flash sensitivity (most likely due to network adaptation) followed by its stabilization. Next, we applied an additional bright 30 s $520 \mathrm{~nm}$ light to bleach $>90 \%$ of $\mathrm{M} / \mathrm{L}$-cone pigment and then monitored the recovery of photopic b-wave sensitivity in darkness. Again, we observed no difference in the rates of cone b-wave flash sensitivity recovery between Irbp ${ }^{+/+} T \alpha^{-/-}$and Irbp ${ }^{-/-} T \alpha^{-/-}$mice, consistent with the results described above. The cone dark adaptation observed with ERG recordings was somewhat slower than that in our transretinal recordings (Fig. $5 C, D$ ), likely due to the partial inhibition of pigment regeneration by anesthetics (Keller et al., 2001) and possibly to slower recovery of the bipolar celldriven cone b-wave compared with photoreceptor a-wave. Nevertheless, these findings demonstrate that the kinetics of mouse $\mathrm{M} / \mathrm{L}$-cone pigment regeneration are not affected by the absence of IRBP.

\section{Rod dark adaptation in IRBP-deficient mice: dependence on RPE65 variant}

As indicated above, all our Irbp ${ }^{+/+} T \alpha^{-/-}$and $\operatorname{Irb} p^{-/-} T \alpha^{-1-}$ mice had the Leu450 variant of RPE65 protein possessing significantly higher retinoid isomerase activity (Redmond et al., 2007) and substantially faster rate of rhodopsin regeneration (Wenzel et al., 2001) compared with its Met450 variant. Therefore, the rate of the slow RPE-dependent phase of cone dark adaptation that we observed in these animals (Fig. 5D) was not compromised by the type of isomerohydrolase. However, our finding of independence of mouse cone dark adaptation on endogenous IRBP motivated us to perform experiments to observe the detrimental effect of IRBP deletion on dark adaptation of rods in mouse strains with a Leu450 variant of RPE65 (Jin et al., 2009) and its absence in mice with the less efficient Met450 isoform of RPE65 (Palczewski et al., 1999; Ripps et al., 2000).

We compared the rates of in vivo rod dark adaptation (driven by recycling of 11-cis-retinal in the RPE) between control 129S2/Sv (Leu450 variant of RPE65) and C57BL/6 (Met450 variant of RPE65) mice and the corresponding Irbp ${ }^{-/-}$strains. By using ERG, we monitored the recovery of rod a-wave amplitude (Fig. $7 A, B$ ) and flash sensitivity (Fig. $7 C, D$ ) after a $>90 \%$ rhodopsin bleach. The initial rate of rod a-wave amplitude recovery was not affected by the deletion of IRBP for both strains. However, rod recovery was approximately two times faster in 129 S2/Sv mice compared with that in C57BL/6 animals (Fig. $7 A, B$, compare slopes of colored vs black lines; see the legend for details), consistent with a faster RPE65-catalyzed isomerohydrolase reaction in this mouse strain. Notably, the deletion of IRBP affected the amplitude recovery in 129S2/Sv mice (the final recovery level was $\sim 1.6$ times higher in control animals), but not in C57BL/6 strain. The kinetics of recovery of rod a-wave flash sensitivity was also independent of IRBP in both strains. However, the final level of a-wave sensitivity recovery was higher in 129S2/Sv animals (Fig. 7C,D, compare colored vs black data 
A

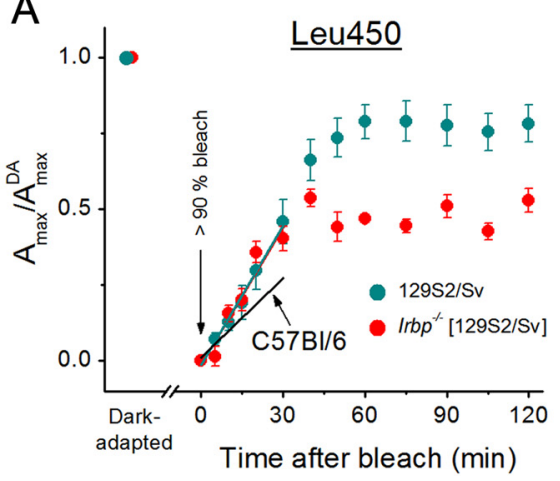

B
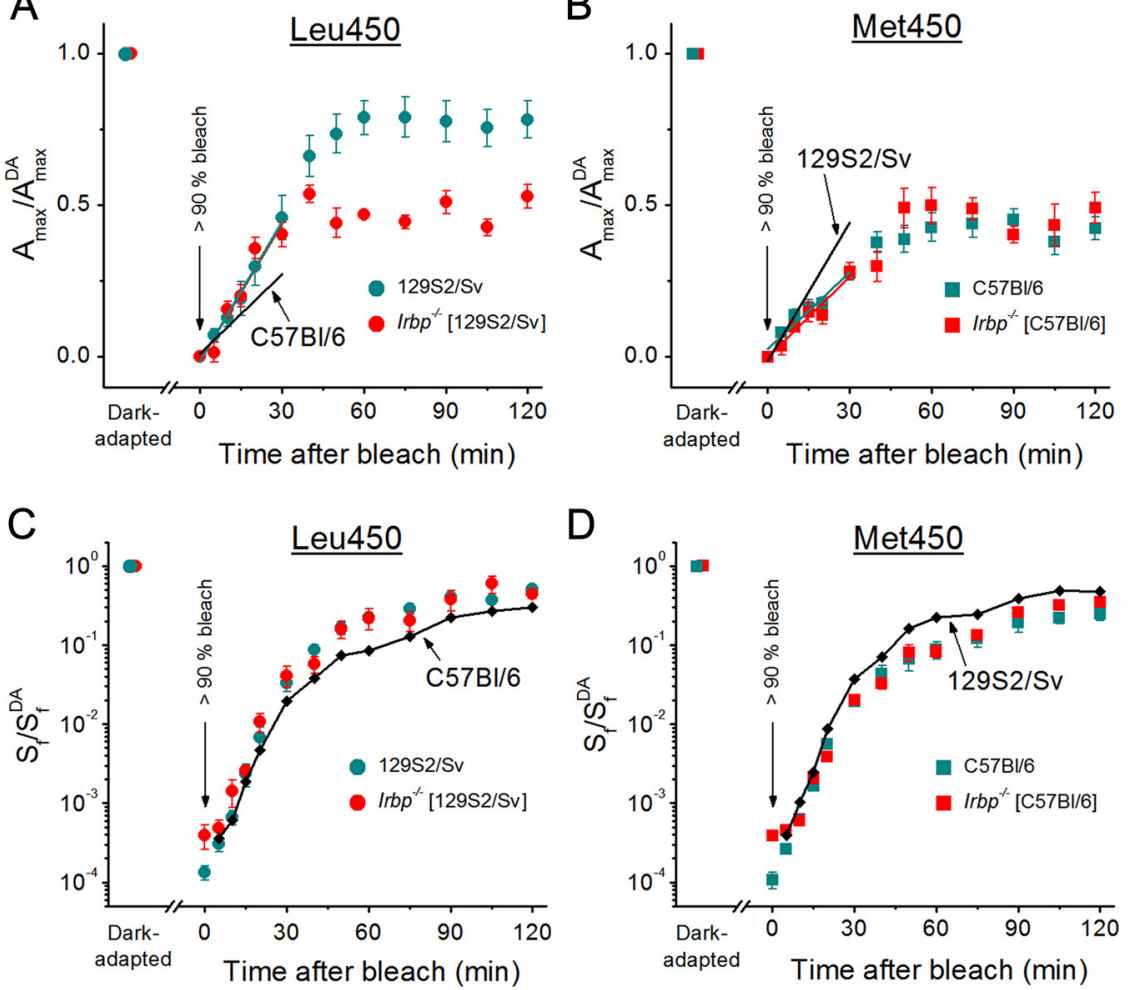

$\mathrm{D}$

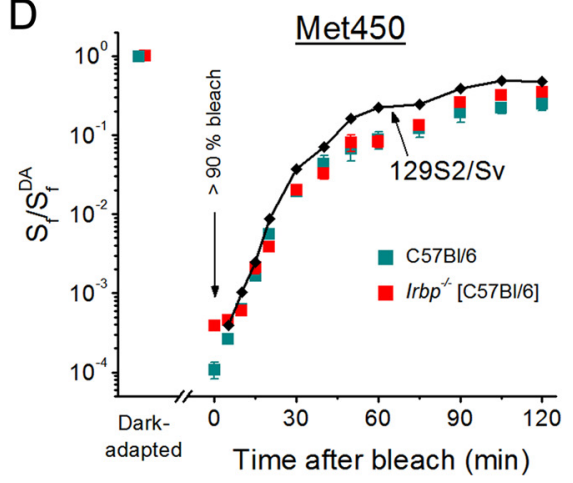

Figure 7. $A-D$, Recovery of rod ERG a-wave amplitude $\left(A_{\max }\right)(\boldsymbol{A}, \boldsymbol{B})$ and $S_{\mathrm{f}}(\boldsymbol{C}, \boldsymbol{D})$ after bleaching $>90 \%$ of rod visual pigment in four strains of mice: $12952 / \mathrm{Sv}$ ( $n=5$ mice) and $/ r b p^{-1-}$ (129S2/Sv background, $n=5$ mice) having a Leu450 variant of RPE65 $(\boldsymbol{A}, \boldsymbol{C}) ; \mathrm{C57BL} / 6\left(n=5\right.$ mice) and $/ \mathrm{rbp}{ }^{-1-}$ (C57BL/6 background, $n=4$ mice) having a Met450 variant of RPE65 (B, D). The parameters were normalized to their dark-adapted values $\left(A_{\max }^{\mathrm{DA}}\right.$ and $\left.S_{\mathrm{f}}^{\mathrm{DA}}\right)$. Bleaching was achieved by $30 \mathrm{~s}$ illumination with 520 $\mathrm{nm}$ LED light at time 0 . All values are means \pm SEM. Data in $\boldsymbol{A}$ and $\boldsymbol{B}$ were corrected for the residual a-wave of $\sim 25-50 \mu \mathrm{V}$, presumably generated by $\mathrm{M} / \mathrm{L}$-cones, that was observed immediately after the bleach. Straight lines in $\boldsymbol{A}$ and $\boldsymbol{B}$ are linear fits to the initial data points (up to $30 \mathrm{~min}$ ): cyan and red lines represent fits to the data from mouse strains indicated in the corresponding legend; black lines indicate averaged fits to the data from the two mouse strains having the opposite variant of RPE65 (shown for comparison of initial rates of dark adaptation). Small black symbols connected with black lines in $($ and $\boldsymbol{D}$ represent averaged data from the two mouse strains having the opposite variant of RPE65 (shown for comparison of $S_{f}$ recovery).

points; see the legend for details). The different effects of IRBP deletion on a-wave amplitude vs flash sensitivity in 129S2/Sv mice is a surprising observation that might potentially be explained by the highly nonlinear relation between these two parameters in mice (Fan et al., 2005). Interestingly, the recovery of the rod response amplitude of Irbp ${ }^{-/-}$mice on Leu450 RPE65 background (Fig. 7A, red circles) was similar to that of both the C57BL/6 control and the Irbp ${ }^{-1-}$ mice on the Met450 RPE65 background (Fig. 7B). Together, these results indicate that the dark adaptation of rods is compromised in IRBP-deficient mouse strains that have the more effective Leu450 variant of RPE65 (e.g., 129S2/Sv strain) but not in mice expressing the less efficient Met450 isoform of RPE65 (C57BL/6). This is in contrast to our findings for $I r b p^{-/-} T \alpha^{-1-}$ mouse cones, whose dark adaptation appears to be normal even in the case of the Leu 450 isoform of RPE65 (Figs. 5, 6).

\section{Discussion}

\section{Relative contributions of the retina and RPE in M/L-cone} pigment regeneration

Cone pigment regeneration occurs via two independent mechanisms. In the canonical visual cycle (Fain et al., 1996; Saari, 2000; Lamb and Pugh, 2004), all-trans-retinol released from cones following exposure to bright bleaching light is recycled to 11-cisretinal in the RPE and then returned to the cone outer segments, where it recombines with cone opsin to regenerate cone visual pigment. This pathway supplies chromophore to both rods and cones and is the only known mechanism for replenishing 11-cis-retinal in rods. A second, cone-specific, mechanism for recycling of chromophore was recently demonstrated to function in amphibian and mammalian retinas, including in the mouse (Wang and Kefalov, 2009; Wang et al., 2009). In this visual cycle, the all-trans-retinol released from bleached cones is recycled into 11-cisretinol in the Müller cells within the neural retina (Mata et al., 2002). In salamander, the RPE and retina visual cycles drive cone pigment regeneration with surprisingly similar rates (Wang et al., 2009). This issue, however, had not been examined in rod-dominant mammalian species where the fraction of cones $(\sim 3 \%$ in mice) is generally substantially smaller than in amphibians $(\sim 30 \%)$. To investigate the relative contributions of the retina and RPE visual cycles in mouse cone dark adaptation, we recorded transretinal cone responses from intact eyecups. This configuration allowed us to record the recovery of mouse cone a-wave flash sensitivity from eyecup, driven by the combined actions of the RPE and retina visual cycles, and compare it with the dark adaptation of cones in isolated retina, driven exclusively by the retina visual cycle.

We found that mouse M/L-cone dark adaptation is biphasic, with an initial rapid component (with a time constant of $\sim 1.5 \mathrm{~min}$ ) (Fig. $5 \mathrm{C}$ ) driven by the retina visual cycle. The kinetics of our retina-driven recovery are somewhat faster than previously reported (Wang and Kefalov, 2009; Wang et al., 2009), most likely due to the use of brighter bleaching light, which allowed us to shorten the bleach exposure from 40 to $3 \mathrm{~s}$, thus unmasking the early rapid recovery of cone sensitivity. Notably, the retina visual cycle alone was not able to promote the complete cone dark adaptation following a bleach. Thus, the mouse retina visual cycle appears critical for the rapid regeneration of cone pigment during dark adaptation but insufficient for full pigment regeneration. In contrast, the RPE visual cycle produced a second, substantially slower component of cone recovery (with a time constant of $\sim 12 \mathrm{~min}$ ) (Fig. $5 \mathrm{D}$ ), and its action was required for near complete cone dark adaptation. Thus, our results indicate that the retina and RPE visual cycles proceed with different kinetics and have distinct roles in mice so that the early cone recovery following a bleach is dominated by the retina visual cycle, whereas the late recovery is dominated by the RPE visual cycle. The faster pigment regeneration via the retina visual cycle is consistent with previous biochemical work suggesting that it could be as much as 20 -fold faster than the RPE visual cycle (Mata et al., 2002). Our results also suggest that a deficiency in the retina visual cycle would be expected to slow down cone dark adaptation, whereas a deficiency in the RPE visual cycle would be ex- 
pected to result in incomplete cone pigment regeneration and the accumulation of free opsin.

\section{IRBP does not modulate $\mathrm{M} / \mathrm{L}$-cone pigment regeneration}

The role of IRBP in accelerating the turnover of visual chromophore and pigment regeneration has been a subject of active research but has remained controversial. IRBP, which constitutes $>70 \%$ of the soluble proteins of the interphotoreceptor matrix (Pfeffer et al., 1983), has long been believed to play an important role in the intercellular trafficking of the hydrophobic retinoids (for review, see Gonzalez-Fernandez, 2003). IRBP binds both 11-cis-and all-trans chromophores and the relative cis-/transretinoid binding distribution is light dependent (Adler and Spencer, 1991). Furthermore, IRBP can facilitate the delivery of all-transretinol from rods to the RPE, the transport of 11-cis-retinal from the RPE to rods (for review, see Pepperberg et al., 1993), and the delivery of 11-cis-retinol to $\mathrm{Nrl}$ cones (Parker et al., 2011). Notably, the native IRBP ligand consists of almost equal fractions of 11-cis-retinal and 11-cis-retinol (Lin et al., 1989), the form of chromophore presumably delivered from Müller cells to cones. Thus, IRBP has the potential to serve as a chromophore carrier in the retina visual cycle and to accelerate cone pigment regeneration.

Despite all circumstantial evidence for a role of IRBP in the trafficking of retinoids in and out of photoreceptors, studies with IRBP-deficient mice have yielded conflicting results. The initial characterization of IRBP knock-out mice revealed that the rates of rod pigment regeneration (Palczewski et al., 1999) and rod dark adaptation (Ripps et al., 2000) are not affected. A recent study by Jin et al. (2009) added a layer of complexity by demonstrating that the isoform of RPE65 affects the phenotype of IRBPdeficient mice. Notably, cone function is compromised in Irbp ${ }^{-1-}$ mice, though there is no agreement on the exact effects. Parker et al. (2009) found a reduction in cone ERG responses in Irbp ${ }^{-1-}$ mice having the less efficient Met450 variant of RPE65 but observed no change in cone density or cone opsin levels and distribution. In contrast, Jin et al. (2009) found that in addition to reduced ERG responses, cones in Irbp ${ }^{-1-}$ mice with more efficient Leu450 variant of RPE65 also had reduced outer segment length and partially mislocalized cone opsin, and underwent progressive degeneration. Both studies suggested retinoid deficiency as a cause for the impaired cone function in the absence of IRBP.

Our results also demonstrate reduction in the M/L-conedriven photoresponse from the mouse retina in the absence of IRBP (Fig. 3). We found the number of cones and their opsin distribution unperturbed in $\operatorname{Irbp} \mathrm{p}^{-1-} \mathrm{T}^{-1-}$ mice (Figs. 1, 2) even though they were on the Leu450 RPE65 background. Notably, their normalized cone sensitivity was actually slightly higher than in control cones (Fig. $4 A, B$ ), probably due to their slowed response inactivation (Fig. $4 C, D$ ). This finding argues against major chromophore deficiency in cones of our Irbp ${ }^{-/-} T \alpha^{-1-}$ animals. This conclusion was further supported by the absence of substantial effect of supplementation of our Irbp ${ }^{-{ }^{-}} T \alpha^{-\prime-}$ mice with exogenous 9-cis-retinal on both amplitude and sensitivity $\left(I_{1 / 2}\right)$ of M/L-cone transretinal response (our unpublished results). An even stronger evidence for efficient cone visual cycle comes from the normal kinetics of cone dark adaptation in IRBPdeficient retinas and eyecups following an intense bleach (Figs. $5 C, D, 6 B$ ) as well as the normal ability of cones from mutant mice to sustain their flash sensitivity in steady bright light (Fig. 6A,B). Together, these results indicate that IRBP does not accelerate mouse $\mathrm{M} / \mathrm{L}$-cone pigment regeneration via either the retina or the RPE visual cycle. Thus, while IRBP clearly plays a role in retina development (Ripps et al., 2000), protects both the isomerization and oxidation state of the chromophore (Crouch et al., 1992; Parker et al., 2011), and affects the overall level of chromophore in photoreceptors (Jin et al., 2009; Parker et al., 2009), the normal regeneration of cone pigment in Irbp ${ }^{-1-} \mathrm{T}^{-\prime-}$ mice argues against a major role of IRBP in the M/L-cone visual cycle.

\section{Role of RPE65 isoform in rod and cone pigment regeneration}

Part of the controversy about the role of IRBP in rhodopsin regeneration through the RPE visual pathway stems from the fact that the isoform of RPE65, a key enzyme of the RPE visual cycle, affects the overall kinetics of the mouse rod visual cycle (Wenzel et al., 2001). Thus, while the early studies of $I r b p^{-\prime-}$ rods done in the less efficient (Met450) isoform of RPE65 revealed no phenotype (Palczewski et al., 1999; Ripps et al., 2000), a subsequent study of the same mice on more effective Leu450 RPE65 isoform background clearly demonstrated a retarded chromophore turnover between rods and the RPE (Jin et al., 2009). Consistent with these results, we also found that the dark adaptation of rods is compromised only in IRBP-deficient 129S2/Sv mouse strain with the Leu450 variant of RPE65 but not in C57BL/6 mice expressing the Met450 isoform of RPE65 (Fig. 7). The dependence of cone pigment regeneration on RPE65 isoform has not been previously investigated. Our findings demonstrating normal dark and light adaptation of mouse M/L-cones (Figs. 5, 6) were obtained on Irbp ${ }^{-1-} T \alpha^{-/-}$animals that have the more efficient Leu 450 variant of RPE65. Thus, unlike the case in rods, the Leu450 isoform of RPE65 is not critical for the fast turnover of chromophore in $\mathrm{M} / \mathrm{L}$-cones. This conclusion is further supported by the only slightly reduced photopic visual acuity in mice lacking IRBP (Table 1), which might be partially caused by slower cone response inactivation (hence, longer integration time) in mutant mice (Figs. 3, 4). Thus, only the slow RPE visual cycle is affected by the isoform of RPE65 while the kinetics of cone dark adaptation, as we show here, are dominated by the more rapid retina visual cycle.

\section{References}

Adler AJ, Spencer SA (1991) Effect of light on endogenous ligands carried by interphotoreceptor retinoid-binding protein. Exp Eye Res 53:337-346.

Applebury ML, Antoch MP, Baxter LC, Chun LL, Falk JD, Farhangfar F, Kage K, Krzystolik MG, Lyass LA, Robbins JT (2000) The murine cone photoreceptor: a single cone type expresses both $\mathrm{S}$ and $\mathrm{M}$ opsins with retinal spatial patterning. Neuron 27:513-523.

Calvert PD, Krasnoperova NV, Lyubarsky AL, Isayama T, Nicoló M, Kosaras B, Wong G, Gannon KS, Margolskee RF, Sidman RL, Pugh EN Jr, Makino CL, Lem J (2000) Phototransduction in transgenic mice after targeted deletion of the rod transducin alpha-subunit. Proc Natl Acad Sci U S A 97:13913-13918.

Carter-Dawson LD, LaVail MM (1979) Rods and cones in the mouse retina. I. Structural analysis using light and electron microscopy. J Comp Neurol 188:245-262.

Crouch RK, Hazard ES, Lind T, Wiggert B, Chader G, Corson DW (1992) Interphotoreceptor retinoid-binding protein and alpha-tocopherol preserve the isomeric and oxidation state of retinol. Photochem Photobiol $56: 251-255$

Duncan T, Fariss RN, Wiggert B (2006) Confocal immunolocalization of bovine serum albumin, serum retinol-binding protein, and interphotoreceptor retinoid-binding protein in bovine retina. Mol Vis 12:1632-1639.

Fain GL, Matthews HR, Cornwall MC (1996) Dark adaptation in vertebrate photoreceptors. Trends Neurosci 19:502-507.

Fan J, Woodruff ML, Cilluffo MC, Crouch RK, Fain GL (2005) Opsin activation of transduction in the rods of dark-reared Rpe65 knockout mice. J Physiol 568:83-95.

Fleisch VC, Neuhauss SC (2010) Parallel visual cycles in the zebrafish retina. Prog Retin Eye Res 29:476-486. 
Fong SL, Liou GI, Landers RA, Alvarez RA, Bridges CD (1984) Purification and characterization of a retinol-binding glycoprotein synthesized and secreted by bovine neural retina. J Biol Chem 259:6534-6542.

Gonzalez-Fernandez F (2003) Interphotoreceptor retinoid-binding protein - an old gene for new eyes. Vision Res 43:3021-3036.

Grimm C, Wenzel A, Stanescu D, Samardzija M, Hotop S, Groszer M, Naash M, Gassmann M, Remé C (2004) Constitutive overexpression of human erythropoietin protects the mouse retina against induced but not inherited retinal degeneration. J Neurosci 24:5651-5658.

Jin M, Li S, Nusinowitz S, Lloyd M, Hu J, Radu RA, Bok D, Travis GH (2009) The role of interphotoreceptor retinoid-binding protein on the translocation of visual retinoids and function of cone photoreceptors. J Neurosci 29:1486-1495.

Keller C, Grimm C, Wenzel A, Hafezi F, Remé C (2001) Protective effect of halothane anesthesia on retinal light damage: inhibition of metabolic rhodopsin regeneration. Invest Ophthalmol Vis Sci 42:476-480.

Kolesnikov AV, Fan J, Crouch RK, Kefalov VJ (2010) Age-related deterioration of rod vision in mice. J Neurosci 30:11222-11231.

Lamb TD, Pugh EN Jr (2004) Dark adaptation and the retinoid cycle of vision. Prog Retin Eye Res 23:307-380.

Lin ZS, Fong SL, Bridges CD (1989) Retinoids bound to interstitial retinolbinding protein during light and dark-adaptation. Vision Res 29:1699-1709.

Liou GI, Fei Y, Peachey NS, Matragoon S, Wei S, Blaner WS, Wang Y, Liu C, Gottesman ME, Ripps H (1998) Early onset photoreceptor abnormalities induced by targeted disruption of the interphotoreceptor retinoidbinding protein gene. J Neurosci 18:4511-4520.

Mata NL, Radu RA, Clemmons RC, Travis GH (2002) Isomerization and oxidation of vitamin A in cone-dominant retinas: a novel pathway for visual-pigment regeneration in daylight. Neuron 36:69-80.

Nikonov SS, Kholodenko R, Lem J, Pugh EN Jr (2006) Physiological features of the $\mathrm{S}$ - and $\mathrm{M}$-cone photoreceptors of wild-type mice from singlecell recordings. J Gen Physiol 127:359-374.

Nymark S, Heikkinen H, Haldin C, Donner K, Koskelainen A (2005) Light responses and light adaptation in rat retinal rods at different temperatures. J Physiol 567:923-938.

Palczewski K, Van Hooser JP, Garwin GG, Chen J, Liou GI, Saari JC (1999) Kinetics of visual pigment regeneration in excised mouse eyes and in mice with a targeted disruption of the gene encoding interphotoreceptor retinoid-binding protein or arrestin. Biochemistry 38:12012-12019.

Parker RO, Fan J, Nickerson JM, Liou GI, Crouch RK (2009) Normal cone function requires the interphotoreceptor retinoid binding protein. J Neurosci 29:4616-4621.

Parker R, Wang JS, Kefalov VJ, Crouch RK (2011) IRBP is the physiologically relevant carrier of 11-cis-retinol in the cone visual cycle. J Neurosci 31:4714-4719.
Pepperberg DR, Okajima TL, Wiggert B, Ripps H, Crouch RK, Chader GJ (1993) Interphotoreceptor retinoid-binding protein (IRBP). Molecular biology and physiological role in the visual cycle of rhodopsin. Mol Neurobiol 7:61-85.

Pfeffer B, Wiggert B, Lee L, Zonnenberg B, Newsome D, Chader G (1983) The presence of a soluble interphotoreceptor retinol-binding protein (IRBP) in the retinal interphotoreceptor space. J Cell Physiol 117: 333-341.

Prusky GT, Alam NM, Beekman S, Douglas RM (2004) Rapid quantification of adult and developing mouse spatial vision using a virtual optomotor system. Invest Ophthalmol Vis Sci 45:4611-4616.

Redmond TM, Wiggert B, Robey FA, Nguyen NY, Lewis MS, Lee L, Chader GJ (1985) Isolation and characterization of monkey interphotoreceptor retinoid-binding protein, a unique extracellular matrix component of the retina. Biochemistry 24:787-793.

Redmond TM, Weber CH, Poliakov E, Yu S, Gentleman S (2007) Effect of Leu/Met variation at residue 450 on isomerase activity and protein expression of RPE65 and its modulation by variation at other residues. Mol Vis 13:1813-1821.

Ripps H, Peachey NS, Xu X, Nozell SE, Smith SB, Liou GI (2000) The rhodopsin cycle is preserved in IRBP "knockout" mice despite abnormalities in retinal structure and function. Vis Neurosci 17:97-105.

Saari JC (2000) Biochemistry of visual pigment regeneration: the Friedenwald lecture. Invest Ophthalmol Vis Sci 41:337-348.

Sillman AJ, Ito H, Tomita T (1969) Studies on the mass receptor potential of the isolated frog retina. I. General properties of the response. Vision Res 9:1435-1442.

Tang PH, Fan J, Goletz PW, Wheless L, Crouch RK (2010) Effective and sustained delivery of hydrophobic retinoids to photoreceptors. Invest Ophthalmol Vis Sci 51:5958-5964.

Umino Y, Solessio E, Barlow RB (2008) Speed, spatial, and temporal tuning of rod and cone vision in mouse. J Neurosci 28:189-198.

Wang JS, Kefalov VJ (2009) An alternative pathway mediates the mouse and human cone visual cycle. Curr Biol 19:1665-1669.

Wang JS, Kefalov VJ (2011) The cone-specific visual cycle. Prog Retin Eye Res 30:115-128.

Wang JS, Estevez ME, Cornwall MC, Kefalov VJ (2009) Intra-retinal visual cycle required for rapid and complete cone dark adaptation. Nat Neurosci 12:295-302.

Wenzel A, Reme CE, Williams TP, Hafezi F, Grimm C (2001) The Rpe65 Leu450Met variation increases retinal resistance against light-induced degeneration by slowing rhodopsin regeneration. J Neurosci 21:53-58.

Zhang H, Fan J, Li S, Karan S, Rohrer B, Palczewski K, Frederick JM, Crouch RK, Baehr W (2008) Trafficking of membrane-associated proteins to cone photoreceptor outer segments requires the chromophore 11-cisretinal. J Neurosci 28:4008-4014. 